\title{
PARÁMETROS BIOLÓGICOS Y POBLACIONALES DE LOS ÁFIDOS MYZUS PERSICAE (SULZER) Y APHIS FABAE SCOP OLI (HEMIPTERA: APHIDIDAE) SOBRE CULTIVARES DE REMOLACHA (BETA VULGARIS L.) (CARYOPHYLLALES: AMARANTHACEAE) Y POROTO (PHASEOLUS VULGARIS L.) (FABALES: FABACEAE) EN CONDICIONES CONTROLADAS.
}

\author{
LOPEZ, M. C. ${ }^{1}$; KAHAN, A. ${ }^{1}$; VASICEK, A. ${ }^{1}$ \& LA LOSSA, F. ${ }^{2}$
}

\begin{abstract}
RESUMEN
El Pulgón Verde del Duraznero (Myzus persicae (Sulzer)) y el Pulgón Negro de las Leguminosas (Aphis fabae Scopoli) son plagas polífagas que transmiten virus y afectan la fisiologia de las plantas hospederas. El objetivo del trabajo fue obtener y comparar los parámetros biológicos y poblacional de ambas especies de áfidos en los cultivares Early Wonder y Green Top Bunching de remolacha, Blue Kentucky y Sofia de poroto chaucha. Las crías se realizaron partiendo de 40 ninfas neonatas por especie de áfido y cultivar, dispuestas individualmente en jaulas que contenían una planta con 3 hojas verdaderas. Se registraron diariamente los eventos de nacimiento, los cambios de estadio hasta la muerte de última hembra de cada cohorte. Se calcularon: tasa intrínseca de incremento natural $\left(\mathrm{r}_{\mathrm{m}}\right)$, tasa neta de reproducción $\left(R_{0}\right)$, tiempo generacional medio $(T)$, tasa finita de incremento $(\lambda$ y tiempo de duplicación (TD). El análisis estadístico se utilizó: test de Student $(\alpha=0,05)$. Se concluye que $A$. fabae y $M$ persicae, tendrian incrementos poblacionales menores sobre Sofia y Early Wonder, respectivamente.
\end{abstract}

Palabras claves: A. fabae, M. persicae, remolacha, poroto, parámetros poblacionales.

1.- Cátedra de Zoología Agrícola, Facultad de Ciencias Agrarias y Forestales (UNLP). Calle 60 y 119 C. C. 31. (1900) La Plata, provincia de Buenos Aires. Email: zooagricola@agro.unlp.edu.ar 2.- IMYZA-CICVyA-INTA. C. C. 25. (1712) Castelar, Provincia de Buenos Aires. email: rlarossa@enia.inta.gov.ar

Manuscrito recibido el 23 de agosto de 2011 y aceptado para su publicación el 20 de octubre de 2011 . 